\title{
The impact of participation restrictions on everyday life in long-term colorectal cancer survivors in the EnCoRe study
}

Citation for published version (APA):

Breedveld-Peters, J. J. L., Bours, M. J. L., Cords, C., Ditters, I. A. M., Habraken, V., Jongen, M. W. J., \& Weijenberg, M. P. (2020). The impact of participation restrictions on everyday life in long-term colorectal cancer survivors in the EnCoRe study: A mixed-method study. European Journal of Oncology Nursing, 45, [101724]. https://doi.org/10.1016/j.ejon.2020.101724

Document status and date:

Published: 01/04/2020

DOI:

10.1016/j.ejon.2020.101724

Document Version:

Publisher's PDF, also known as Version of record

\section{Document license:}

Taverne

\section{Please check the document version of this publication:}

- A submitted manuscript is the version of the article upon submission and before peer-review. There can be important differences between the submitted version and the official published version of record.

People interested in the research are advised to contact the author for the final version of the publication, or visit the DOI to the publisher's website.

- The final author version and the galley proof are versions of the publication after peer review.

- The final published version features the final layout of the paper including the volume, issue and page numbers.

Link to publication

\footnotetext{
General rights rights.

- You may freely distribute the URL identifying the publication in the public portal. please follow below link for the End User Agreement:

www.umlib.nl/taverne-license

Take down policy

If you believe that this document breaches copyright please contact us at:

repository@maastrichtuniversity.nl

providing details and we will investigate your claim.
}

Copyright and moral rights for the publications made accessible in the public portal are retained by the authors and/or other copyright owners and it is a condition of accessing publications that users recognise and abide by the legal requirements associated with these

- Users may download and print one copy of any publication from the public portal for the purpose of private study or research.

- You may not further distribute the material or use it for any profit-making activity or commercial gain

If the publication is distributed under the terms of Article 25fa of the Dutch Copyright Act, indicated by the "Taverne" license above, 


\title{
The impact of participation restrictions on everyday life in long-term colorectal cancer survivors in the EnCoRe study: A mixed-method study
}

\author{
Jose J.L. Breedveld-Peters (PhD)*, Martijn J.L. Bours (PhD), Charlotte I. Cords (MSc) ${ }^{1}$, \\ Imke A.M. Ditters (MSc) ${ }^{1}$, Vera Habraken (MSc) ${ }^{1}$, Michelle W.J. Jongen (MSc) ${ }^{1}$, \\ Matty P. Weijenberg (PhD) \\ Department of Epidemiology, GROW-School for Oncology and Developmental Biology, Maastricht University, Maastricht, the Netherlands
}

\section{A R T I C L E I N F O}

\section{Keywords:}

Societal participation

Participation restrictions

International classification of functioning

Disability and health

Colorectal cancer survivor

\begin{abstract}
A B S T R A C T
Purpose: Knowledge about long-term colorectal cancer (CRC) or treatment related health and functioning problems and on its impact on participation of CRC survivors in domestic life and in society is limited. We aimed to explore the nature and impact of cancer (treatment) related participation restrictions on everyday life of longterm CRC survivors, their current satisfaction with participation, and associations of health and functioning problems with participation satisfaction, using the International Classification of Functioning, Disability and Health (ICF) to comprehensively study participation.

Method: Mixed-method study in 2-10 years post-diagnosis stage I-III CRC survivors ( $\mathrm{n}=151$ ) from the crosssectional part of the EnCoRe study. Participation restrictions were explored by semi-structured interviews in a subsample reporting participation restrictions $(n=10)$. Role functioning (SF36-Health Survey), fatigue (Checklist Individual Strength), and peripheral neuropathy symptoms (EORTC QLQ-CIPN20) were assessed in all participants and associations with self-reported participation satisfaction were analyzed by multivariable logistic regression models.

Results: $19 \%$ of CRC survivors reported dissatisfaction with participation. Participation restrictions were reported for interpersonal relationships, work/employment, and social/civic life. CRC survivors reporting better physical and emotional role functioning were significantly less likely to be dissatisfied with their participation, whereas survivors reporting higher levels of fatigue or more peripheral neuropathy symptoms were more likely to be dissatisfied with participation.

Conclusions: Colorectal cancer (treatment) related health and functioning problems negatively impacts the ability of nearly 1 in 5 long-term CRC survivors to participate in everyday life situations and their satisfaction with participation. Follow-up care needs to be able to identify and address these problems.
\end{abstract}

\section{Introduction}

Following diagnosis and treatment, colorectal cancer (CRC) survivors often experience persisting health and functioning problems due to the cancer and its treatment, such as gastrointestinal problems, cancerrelated fatigue, symptoms of chemotherapy-induced peripheral neuropathy (CIPN), and reduced physical and emotional functioning
(Altschuler et al., 2009; Averyt and Nishimoto, 2014; Bols et al., 2015; Caravati-Jouvenceaux et al., 2011; Denlinger and Barsevick, 2009; Desnoo and Faithfull, 2006; Domati et al., 2011; Drury et al., 2017; Grant et al., 2011; Harrington et al., 2010; Jansen et al., 2010; LeMasters et al., 2014; McCaughan et al., 2012; McMullen et al., 2008; Mols et al., 2014a,b; Nikoletti et al., 2008; Ramirez et al., 2009; Sweeney et al., 2006). These problems can severely limit the ability of

\footnotetext{
${ }^{*}$ Corresponding author. Maastricht University, Department of Epidemiology, GROW School for Oncology and Developmental Biology, P. Debyeplein 1, 6229 HA Maastricht, The Netherlands, P.O. Box 616, 6200, MD, Maastricht, the Netherlands.

E-mail addresses: jose.breedveld@maastrichtuniversity.nl (J.J.L. Breedveld-Peters), m.bours@maastrichtuniversity.nl (M.J.L. Bours), c.cords@alumni.maastrichtuniversity.nl (C.I. Cords), i.ditters@alumni.maastrichtuniversity.nl (I.A.M. Ditters), v.habraken@alumni.maastrichtuniversity.nl (V. Habraken), mwj.jongen@alumni.maastrichtuniversity.nl (M.W.J. Jongen), mp.weijenberg@maastrichtuniversity.nl (M.P. Weijenberg).

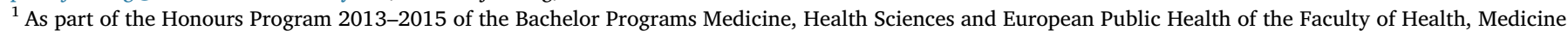
and Life Sciences, Maastricht University.
} 
CRC survivors to perform daily activities such as self-care, and may restrict their level of participation in life situations. This refers to their ability to participate in domestic life (such as performing household tasks), to function as a member of society (e.g. the capacity to work), and to participate in interpersonal interactions and relationships, and in community and social events (World Health Organization, 2001). However, until now it remains mostly unknown how health and functioning problems influence participation of long-term CRC survivors. Moreover, it is of importance to know what health and functioning problems mean to CRC survivors, whether or not CRC survivors are satisfied with their current participation, as well as factors related to their level of satisfaction, to inform development of strategies to address participation problems of CRC survivors.

Research on CRC survivors' satisfaction with participation is limited. Those studies are usually performed in mixed populations of cancer survivors, focus on specific aspects of participation (and implicitly satisfaction with participation), for example on social (Wright et al., 2005) or work-related difficulties only (McGrath et al., 2017; Rasmussen and Elverdam, 2008), or use specific theoretical models. A study of Devins in six common cancers, including gastrointestinal cancer, using the illness intrusiveness model, concludes that the psychosocial impact of a chronic life-threatening disease plays a role especially instrumental life domains, like work, finances, and health, and depends on the context in which it is experienced (Devins et al., 2006). A prospective study in CRC survivors observed that low optimism, poorer social support, a more negative cognitive appraisal and younger age were associated with poorer life satisfaction (defined as the participants' subjective cognitive well-being) and health-related quality of life, specifically in a later stage of disease and in females (Dunn et al., 2013). A review of Catt et al. on the impact of cancer on patients' lives in a population with different cancer types, found high levels of financial distress and social difficulties following cancer, but also the need for studies investigating patient-reported outcomes focusing on roles and responsibilities (e.g. related to work) (Catt et al., 2017).

For the ongoing cohort study in CRC survivors, the International Classification of Functioning, Disability and Health (ICF) of the World Health Organizanion (WHO) has been applied as a theoretical framework, to systematically and comprehensively study lifestyle and healthrelated quality of life in CRC survivors. Factors relevant to study lifestyle and health related quality of life factors in CRC survivors were identified from the literature and mapped within the ICF framework, to develop an ICF-based conceptual model. Next, study measures were selected based on this conceptual model, and the items of these measures were linked to the ICF model. This was done to determine whether the items that are part of the (sub)domains of the ICF, including social participation, were sufficiently covered by the chosen measurements (van Roekel et al., 2014). For this study, we used measures that were linked to the domains of body functions and structures, activities and participation of the ICF. The ICF is a useful holistic framework for cancer survivorship research, and is allowing us to comprehensively study participation restrictions and satisfaction with participation in relation to CRC and its treatment. In this bio-psychosocial framework, an individual's level of functioning is described using different domains (body functions and structures, activities, and participation). These domains are regarded as essential components of health. Importantly, the ICF framework focuses not only on physical aspects of health and functioning, but also on more qualitative features such as psychological and social functioning, put in the context of relevant environmental and personal factors that influence an individual's health and functioning (Stephenson and Richardson, 2008) (Kostanjsek, 2011). Furthermore, the ICF framework can be applied both in research practice and in clinical practice, facilitating translation of findings to future survivorship care.

The present study aimed to investigate participation, as defined in the ICF framework comprising domestic life, social participation, labor participation, community participation and recreation and leisure, in long-term (2-10 years post-diagnosis) CRC survivors using a mixedmethods approach. To explore how persistent problems in CRC survivors potentially affect satisfaction with participation, we investigated quantitative associations of physical and emotional role functioning, fatigue, and CIPN with CRC survivors' satisfaction with participation. Next, to get additional insight and to illustrate findings, we qualitatively explored the impact of health and functioning problems resulting from the cancer and its treatment on the current participation of CRC survivors.

\section{Methods}

\subsection{Study design and participants}

Data was used from the cross-sectional part of the Energy for Life after Colorectal cancer (EnCoRe) study, in long term stage I to III CRC survivors, 2-10 years post diagnosis, which was initiated in 2012 at Maastricht University in the Netherlands. Methods of our study have been described in detail elsewhere (van Roekel et al., 2014). The ICF framework is used as the theoretical basis in the EnCoRe-study to systematically and comprehensively study lifestyle and health-related quality of life in CRC survivors (See Fig. 1).

In brief, eligible subjects were individuals diagnosed with and treated for CRC (stage I-III), between 2002 and 2010 at Maastricht University Medical Center + (MUMC +), the Netherlands, 2-10 years earlier. These individuals were preselected via the Netherlands Cancer Registry (NCR; managed by Comprehensive Cancer Centre the Netherlands) and approached by their Medial Doctor first by mail and then by telephone by a study team member for participation. A home visit was planned in case of willingness to participate, during which written informed consent was obtained before the start of the study measurements that were performed at participants' homes. Data on lifestyle behavior and related factors (diet, physical activity, and body composition) and patient reported outcomes such as health related quality of life were assessed by validated questionnaires. The EnCoRe study had been approved by the Medical Ethics Committee of the University Hospital Maastricht and Maastricht University, the Netherlands. Data collection was performed in 2012 and 2013.

An additional qualitative study was carried out in 2014 and 2015 using subjects from the study population of the cross-sectional EnCoRe study. Eligible subjects for the qualitative study were participants of the cross-sectional study, who previously reported participation restrictions. Potential interview candidates were first approached by telephone, after which an information letter for the qualitative study was sent. After one week, potential interview candidates were contacted again by phone to ask whether they had received, and understood the information. After that, a comprehensive explanation of the study content, consent needed for participation and for audiotaping the interview, and information about confidentiality was given. In case interview candidates were willing to participate in this interview, an appointment for the interview was made. Additional written informed consent was obtained for this part of the study from all participants, after detailed information before the start of the interview at the patients' home. Additional approval for the qualitative part of the study was obtained from the Medical Ethics Committee of the University Hospital Maastricht and Maastricht University, the Netherlands.

For the present study a sequential explanatory mixed-method design was applied, to investigate participation in long-term CRC survivors. Participation is defined as the ability to participate in domestic life (such as performing household tasks), to function as a member of society (e.g. the capacity to work), and to participate in interpersonal interactions and relationships, and in community and social events (World Health Organization, 2001). We additionally investigated what health and functioning problems mean to CRC survivors. For this we make use of quantitative data as the basis and additional qualitative data to further explore, and get in-depth insight and understanding. 


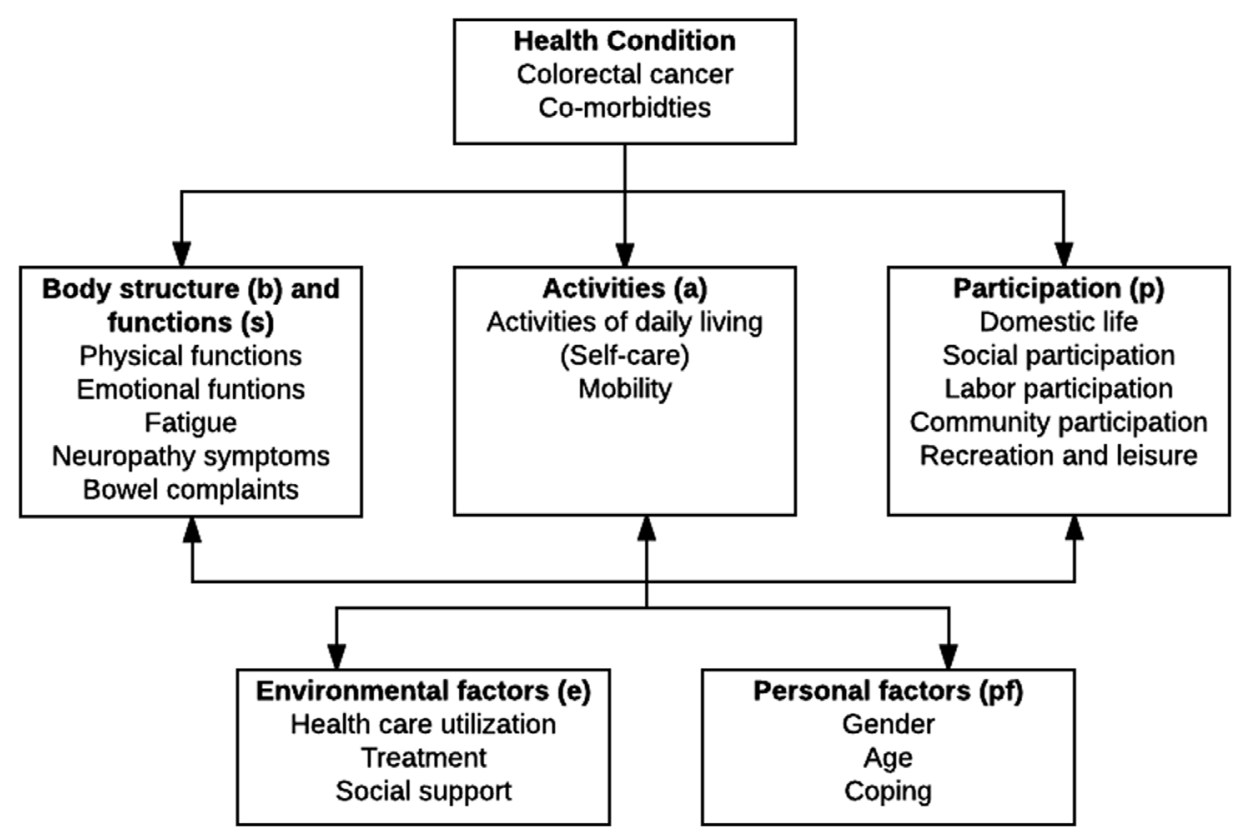

Fig. 1. The International Classification of Functioning, Disability and Health Conceptual model.

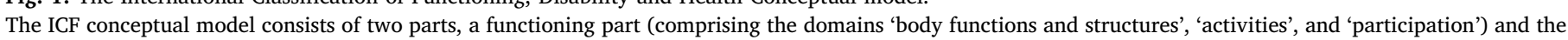
contextual factors (comprising environmental and personal factors).

Results of the qualitative study were connected to quantitative results as additional information for a better understanding of the impact of participation restrictions on health and functioning problems experienced by the group CRC survivors.

Quantitative methods were used to assess CRC survivors' satisfaction with participation, and to analyze associations of physical and emotional role functioning, fatigue and CIPN with participation satisfaction. For the quantitative part, data from all participants of the cross-sectional EnCoRe study was used, which had been collected between May 2012 and December 2013.

The additional qualitative study was carried out using a descriptive approach, to explore the nature and impact of persisting health and functioning problems related to the prior cancer diagnosis and treatment on current participation of CRC survivors. Individual semi-structured face-to-face interviews were performed in a purposive sample of CRC survivors who had participated in the EnCoRe study, who previously reported participation restrictions, and who previously gave permission to be approached again for additional research. Interviews were held between October 2014 and March 2015.

\subsection{Data collection, quantitative part}

Satisfaction with participation was assessed by asking participants to report whether their current satisfaction with participation in paid jobs (yes/no), non-paid jobs (yes/no), household tasks (yes/no), and hobbies (yes/no) was the same as compared to before their CRC diagnosis, reflecting the involvement in major life situations as defined by the ICF. A negative answer to at least one of the questions was considered to reflect dissatisfaction with participation.

\subsubsection{Role functioning, fatigue and chemotherapy-induced peripheral neuropathy}

The level of physical and emotional role functioning (i.e. physical or emotional problems that limit work performance or other daily activities) was measured by the SF-36 Health Survey questionnaire (VanDerzee and Sanderman,). The SF-36 has been validated in, amongst others, cancer patients, and showed consistent support for the validity of the SF-36. The SF-36 has a high internal consistency, with a mean alpha coefficient across all scales and samples of 0.84 (Aaronson et al., 1998). The SF-36 has frequently been used in cancer survivors (Fitzsimmons et al., 2009), and is comprised of subscales for assessing problems in physical role functioning (based on 4 items) and in emotional role functioning (based on 3 items). Item responses per subscale were summed and transformed into a continuous scale ranging from 0 to 100 points, with a higher score indicating less problems (i.e. better physical or emotional role functioning).

Fatigue was assessed by the Checklist Individual Strength (CIS), which was originally developed and validated for patients with chronic fatigue syndrome (Vercoulen et al., 1994, 1996), but has also been applied in cancer survivors (Servaes et al., 2001). The CIS had a high internal consistency in the current population for both the total score (Cronbach's $\alpha=0.93$ ) and the subscales (Cronbach's $\alpha=0.72$ ). The CIS consists of 20 items with 7-point Likert scale response options, which were summed to create a continuous score ranging from 20 to 140 points, with higher scores indicating higher levels of fatigue (Servaes et al., 2001; Vercoulen et al., 1994, 1996).

The 20-item cancer-specific European Organization for the Research and Treatment of Cancer Chemotherapy-Induced Peripheral Neuropathy 20 (EORTC QLQ-CIPN20) questionnaire was used to measure the severity of CIPN symptoms by means of sensory ( 9 items), motor ( 8 items) and autonomic ( 3 items) symptom subscales. Each item is scored on a scale ranging from 1 (not at all) to 4 (very much) symptoms. Item responses were transformed into continuous subscale scores ranging from 0 to 100 points, with higher scores indicating more severe CIPN symptoms. CIPN20 questionnaire has been evaluated for its psychometric properties in multiple studies, showing satisfactory validity, reliability, sensitivity, and responsiveness (Smith et al., 2019, Smith et al., 2018).

\subsubsection{Socio-demographic, lifestyle, and clinical characteristics}

From our previously developed ICF-based conceptual model (van Roekel et al., 2014), other relevant factors for studying participation of CRC survivors were identified and measured, including socio-demographic, lifestyle, and clinical characteristics. Gender, age, living situation (alone yes/no), dietary changes since diagnosis (yes/no), and current smoking status (yes/no) were collected through self-report. Adherence to the Dutch physical activity guidelines ( $>30 \mathrm{~min}$ of moderate-to-vigorous physical activity on at least 5 days per week) was 
assessed by the Short QUestionnaire to ASsess Health-enhancing physical activity (SQUASH) (Wendel-Vos et al., 2003). Body height and weight were measured by trained personnel for calculation of body mass index (BMI, $\mathrm{kg} / \mathrm{m}^{2}$ ). The presence of comorbidities was assessed using the Self-Administered Comorbidity Questionnaire (Sangha et al., 2003), and the presence of a stoma was assessed by self-report. Additional clinical data on cancer stage, tumour localization, and treatment characteristics were collected through the Netherlands Cancer Registry.

\subsection{Data collection, qualitative part}

For the qualitative interviews, a total of 48 out of 151 participants of the cross-sectional EnCoRe study were eligible, since they had previously reported participation restrictions by giving an affirmative answer to one of the four items of the role limitations (due to physical health) scale of the Short Form Health Survey (SF-36) questionnaire, i.e., 'Did you have any trouble with your work or other activities in the past four weeks due to your physical health' (Aaronson et al., 1998; Ware and Sherbourne, 1992). To select interview candidates, we applied the non-probability purposive sampling technique of maximum variation sampling (Etikan, 2016), based on representation of specific characteristics across a broad spectrum for which we wanted to have enough variance. The purposive sample characteristics to be represented in our interview population were age ( $<65$ vs. $\geq 65$ years), gender (male vs. female), tumour stage (I, II and III), presence of comorbidities ( 0,1 , and $\geq 2$ comorbidities), job (paid, unpaid or no job), partner (yes/no), time since diagnosis ( $<5$ vs. $>5$ years), and stoma (yes/no). Interview candidates were selected from the eligible CRC survivors based on the presence of these specific characteristics. Selected interview candidates were contacted by telephone to ask permission for sending a study information letter, and were contacted again after one week to ask whether they agreed to participate in an interview. Characteristics of already included interview participants were kept up to date, and new interview candidates were selected based on the specific characteristics that were still absent or underrepresented in the group of previously interviewed participants, in order to achieve maximum variation of sample characteristics. In that way, a balanced interview population was obtained in which the different characteristics were more or less equally represented. The selection of new interview candidates was continued until data saturation was achieved, which was considered to be the case when two consecutive interviews did not reveal any new data relevant to the research question. Two pilot interviews were executed, and evaluated afterwards. As no adjustments were made in the final design, content and execution of the interview, the data from the pilot interviews were included in the analyses.

The semi-structured interviews in Dutch were conducted using a constructed guide with interview themes, which were based on the topics of the participation domain of our previously constructed conceptual ICF framework (van Roekel et al., 2014) (comprising domestic life, social participation, labor participation, community participation and recreation and leisure), and which were tailored to the present research questions (Supplementary Table 1). Interview themes were focused on the nature of restrictions in participation, such as participation in household tasks, labor participation and participation in social activities and hobbies, experienced by the CRC survivors as a result of their prior cancer and treatment, as well as on the impact of these restrictions on everyday life. Participants were interviewed in their own homes by a trained interviewer, accompanied by an observer who took notes. All interviews were digitally recorded, to enable data transcription and to guarantee transparency. Preceding the interviews, consent was obtained for conducting and audiotaping the interviews from all interview participants.

To ensure rigour, and to make the study transparent and explicit, the study was executed according to standardized procedures for all parts of the study. For example standardized procedures were followed for purposively sampling, for communication with potential interview candidates, for data collection, and for performing data analysis. Logs of activities were kept. All researchers involved were thoroughly trained by experienced researchers, for the different study tasks, including interviewing study participants and performing data analysis. Every single interview was analyzed by two researchers, who independently identified relevant text fragments, summarized texts and attached descriptive codes, mapped codes in the ICF categories. Results of activities were compared systematically and differences were discussed until agreement was reached Checks on appropriate coding were performed by another team member. Lastly, in regular meetings, study execution and findings were discussed within the research team.

\subsection{Data analyses}

\subsubsection{Quantitative data analyses}

Data on satisfaction with participation and socio-demographic, lifestyle and clinical characteristics were described as means and standard deviations (SD) or as absolute (N) and relative (\%) frequencies. Socio-demographic, lifestyle and clinical characteristics were also described in subgroups of participants who were satisfied with their participation or not satisfied.

Multivariable logistic regression analyses were performed to assess the association of physical and emotional role functioning, fatigue, and CIPN as main independent variables with participation satisfaction (yes/no) as binary dependent variable, to obtain odds ratios (OR) reflecting the likelihood of participation satisfaction for clinically relevant increments in the scores of physical or emotional functioning, fatigue or CIPN. Clinically relevant increments were defined as 0.5 times the SD of the scores of main independent variables (Revicki et al., 2008).

Multivariable logistic regression models were adjusted for relevant confounders. Potential confounders were identified from literature and entered in the model in a forward stepwise fashion to evaluate the magnitude of potential confounding. When the change in estimate of the beta was less than $10 \%$, the potential confounding variable was considered not relevant, and excluded from the model. This was the case for Body Mass Index (BMI), stoma, smoking status, living situation, tumor site, tumor stage, and self-reported dietary changes. The final models were adjusted for age (years), gender, number of comorbidities $(0 / 1 / \geq 2)$, and chemotherapy treatment (yes/no). Depending on the main independent variable of interest, models were adjusted further for the other independent variables to determine independent associations (e.g. the association of physical role functioning was adjusted for emotional role functioning and fatigue), except for models with the CIPN symptom subscales as main independent variables because of high correlations between CIPN subscales.

The assumptions for the use of multivariable logistic regression models were tested. The linearity assumption was not violated (Field, 2013), and none of the models showed evidence for multicollinearity (variation inflation factors $\leq 5$ ) (Stine, 1995).

IBM SPSS Statistics version 21 was used and two-sided P-values < 0.05 were considered statistically significant.

\subsubsection{Qualitative data analyses}

A quantitative content analysis was performed on the qualitative data from the semi-structured interviews (Forman and Damschroder, 2008). The recorded interview texts were transcribed verbatim, and notes made by the observer were inserted as comments in the transcript. Text fragments relevant to answer the research question were summarized, and descriptive codes were then assigned to the summarized fragments. Each interview was coded by two researchers. Results of coding were compared and any differences were discussed until consensus was reached. Next, the findings from each individual interview were mapped into the applicable parts of the ICF framework and linked to appropriate ICF categories within the domains 'health condition', 'body structure \& functions, 'activities', 'participation', 
'environmental factors' and 'personal factors', based on published linking rules. The ICF provides a standard language and framework for the description of functioning and disability and health-related and contextual factors. The ICF consists of an extensive list of items and codes per domain and subdomain of functioning, representing a specific aspect of functioning with a standardized definition or description. Linking rules have been developed to facilitate the identification of meaningful concepts in data and to link identified concepts to an ICF code with a description (van Roekel et al., 2014). In this way, separate overviews of ICF categories were created of the main biopsychosocial areas reflecting health and functioning problems related to the CRC diagnosis and treatment influencing participation that were mentioned by each interview participant. As specific classifications for 'personal factors' are not defined yet, we applied own terms, for example 'coping'. An overall summary of interview results was obtained by putting the retrieved ICF categories of all separate overviews together in a single ICF framework. The linking of interview findings to the ICF framework was performed by two researchers. Results of linking to the ICF domains were compared and any differences were discussed until consensus was reached.

\section{Results}

\subsection{Quantitative data}

Between 2002 and 2010, 772 individuals were diagnosed and treated for CRC at Maastricht University Medical Center+ the Netherlands. From this group 52\% was not eligible, due to several reasons (e.g. not alive, co-morbidities that obstruct successful participation such as Alzheimer disease). Eligible individuals $(\mathrm{N}=373)$ were invited to participate in the study, and from this group a total of 155 CRC survivors (42\%) participated in the EnCoRe study, of whom 151 were included in the quantitative data analyses (Fig. 3). As shown in Supplementary Table 2, compared to non-participants, included participants were 3.9 years younger $(P<0.001)$, but did not significantly differ otherwise.

CRC survivors (62.3\% men, Table 1 ) had a mean age of 69.8 years $(\mathrm{SD}=8.7)$ and were on average 5.7 years since CRC diagnosis $(\mathrm{SD}=1.8)$. Nineteen percent of CRC survivors reported to be dissatisfied with their current level of participation. As shown in Table 2, CRC survivors who were dissatisfied with participation had lower physical role functioning and emotional role functioning scores than survivors who reported to be satisfied with participation (33.7 and 61.7 vs. 81.8 and 93.1, respectively). CRC survivors reporting dissatisfaction with participation had higher scores for fatigue than survivors who reported to be satisfied with participation (77.3 vs. 52.1, respectively). Within the subgroup of CRC survivors who had received chemotherapy, more CIPN-related complaints were reported by CRC survivors who were dissatisfied with participation than those who were satisfied (sensory: 37.0 vs. 17.1 , motor: 36.1 vs. 14.3 , and autonomy: 34.4 vs. 9.7, respectively; Table 2).

Results of confounder-adjusted multivariable logistic regression analyses are shown in Table 3. CRC survivors with better physical or emotional role functioning were significantly less likely to be dissatisfied with their current participation $0.6,95 \% \mathrm{CI}$ : $0.5,0.8$; and OR $0.7,95 \%$ CI: $0.5,0.8$, respectively). Additionally, survivors with a higher level of fatigue were more likely to be dissatisfied with participation (OR 1.6, 95\% CI: 1.2, 2.0). Associations for physical and emotional role functioning and fatigue were not significant after adjustment for each other (Table 3). CRC survivors who had received chemotherapy, reported more CIPN symptoms, which was significantly associated with an increased likelihood of dissatisfaction with participation (OR for sensory symptom: 0.6, 95\% CI: 0.5, 0.9; for motor symptoms: $0.6,95 \%$ CI: 0.5, 0.9; and OR for autonomic symptoms: 0.6, 95\% CI: 0.4, 0.8; Table 3).

\subsection{Qualitative data}

For the qualitative interviews, a total of 48 participants of the crosssectional EnCoRe study were eligible since they had previously reported participation restrictions (Fig. 3). Based on data saturation we included 10 study participants in the qualitative part of the study. All approached interview candidates were willing to participate in the interviews. As shown in Table 4, this purposive sample showed a balanced representation of the predefined relevant characteristics. Interviews lasted for on average $1 \mathrm{~h}$.

\subsubsection{Participation restrictions mapped in the ICF conceptual model}

As shown in Fig. 2, participation restrictions related to the CRC diagnosis and treatment were mainly reported during the interviews within the ICF domains of 'D6 Domestic life' regarding participation in household tasks; 'D7 Interpersonal relationships' regarding formal, informal, family, and interpersonal relationships; 'D8 major life areas' with respect to several aspects of work/employment, e.g. maintaining and terminating a job, working hours (full-time/part-time work); and 'D9 Community, social and civic life' with respect to community life, and recreation and leisure (sports, hobbies, arts and culture, crafts).

Additionally, the interview information about activity limitations, impairments in body functions and structures related to the CRC and treatment, as well as barriers and facilitators of environmental and personal factors influencing health and functioning were also mapped in the ICF framework (Fig. 2), showing other relevant factors mentioned by the participants which potentially influenced participation restrictions. It is not surprising that all domains of the ICF are represented because of the interview topics selected based on the ICF framework, but it is of note that most of the interviewed survivors mentioned problems in all domains.

\subsubsection{Nature of participation restrictions and impact on daily life}

Although treatment for CRC had occurred on average almost 7 years ago, interview participants reported about the consequences of the cancer (treatment) they still experienced in their daily lives. Several CRC survivors reported restrictions in participation due to neuropathy as result of the chemotherapy received, changing their lives. CRC survivors said they still had tingling or numb hands and/or feet, resulting in the inability to execute hobbies they used to do before the CRC (treatment), like model making, taking films or photographs, building with building blocks, playing with grandson, repair of watches, and recreational walking, swimming, recreational cycling, and gardening. Like one of the interviewees explained:

'I cannot go anywhere. I am only able to walk up and down the street to take the dog out. I cannot even walk to the mailbox, because of my sore soles. This is worthless.'

Fatigue due to CRC treatment was reported to frequently affect participation as well. Low energy levels were reported. Household tasks were said to be more straining as compared to before CRC treatment. Interviewed survivors indicated a limited ability to execute recreational walking or cycling and an increased time to recover. One person indicated:

'The most difficult thing was that I was no longer able to go cycling with my wife and her sister like before.'

Fatigue impacted interviewed CRC survivors, restricting them in the ability for going out, in the ability to join friends when going e.g. into town or visiting a museum, and limiting possibilities to make appointments and to be with friends due to lack of energy, resulting in a narrow circle of acquaintances. Furthermore, CRC survivors reported lacking stamina to participate in sports, and on the other hand also reported to perform sports to regain health and physical fitness. Fatigue made the participation in sports difficult, as one survivor experienced difficulties in performing all necessary procedures, and another 
Table 1

Socio-demographic and clinical characteristics of colorectal cancer survivors by satisfaction with societal participation yes or No $(\mathrm{n}=151)$.

\begin{tabular}{|c|c|c|c|c|c|c|}
\hline \multicolumn{7}{|l|}{ Satisfaction with societal participation } \\
\hline Overall satisfaction with participation, $\mathrm{n}(\%)$ & 151 & $(100.0)$ & 122 & (80.8) & 29 & $(19.2)$ \\
\hline Satisfaction with paid Job & 26 & $(17.2)$ & 23 & (88.5) & 3 & $(11.5)$ \\
\hline Satisfaction with unpaid job & 35 & $(23.2)$ & 33 & (94.3) & 2 & (5.7) \\
\hline Satisfaction with household tasks & 125 & $(82,8)$ & 110 & (88.0) & 15 & $(12.0)$ \\
\hline Age, years, mean (SD) & 69.8 & $(8.7)$ & 70.1 & (8.7) & 68.1 & $(8.7)$ \\
\hline \multicolumn{7}{|l|}{ Gender, n (\%) } \\
\hline Men & 94 & (62.3) & 80 & (65.6) & 14 & $(48.3)$ \\
\hline Woman & 57 & (37.7) & 42 & (34.4) & 15 & $(51.7)$ \\
\hline Years since diagnosis, mean (SD) & 5.7 & $(1.8)$ & 5.7 & (1.9) & 5.8 & (1.6) \\
\hline \multicolumn{7}{|l|}{ Number of comorbidities, n (\%) } \\
\hline $0, \mathrm{n}(\%)$ & 37 & (24.5) & 34 & (28.1) & 3 & $(10.3)$ \\
\hline Non-current smoker & 135 & (89.4) & 110 & $(90.2)$ & 25 & $(86.2)$ \\
\hline \multicolumn{7}{|l|}{ Meeting Dutch PA guidelines, n (\%) } \\
\hline Yes & 76 & (50.3) & 65 & (53.3) & 11 & $(37.9)$ \\
\hline No & 75 & $(49.7)$ & 57 & (46.7) & 18 & $(62.1)$ \\
\hline \multicolumn{7}{|l|}{ Dietary change after colorectal cancer, $n(\%)$} \\
\hline Yes & 54 & $(35.8)$ & 42 & (34.4) & 12 & $(41.4)$ \\
\hline No & 97 & $(64.2)$ & 80 & (65.6) & 17 & $(58.6)$ \\
\hline \multicolumn{7}{|l|}{ Cancer stage, n (\%) } \\
\hline Stage I & 42 & (29.4) & 35 & (30.7) & 7 & $(24.1)$ \\
\hline Stage II & 52 & (36.4) & 42 & (36.8) & 10 & $(34.5)$ \\
\hline Stage III & 49 & (34.3) & 37 & (32.5) & 12 & (41.4) \\
\hline \multicolumn{7}{|l|}{ Location of tumor, $\mathrm{n}(\%)$} \\
\hline Colon & 80 & (53.0) & 66 & (54.1) & 14 & $(48.3)$ \\
\hline Rectum and recto-sigmoid & 71 & $(47.0)$ & 56 & (45.9) & 15 & $(51.7)$ \\
\hline \multicolumn{7}{|l|}{ Stoma, n (\%) } \\
\hline
\end{tabular}

Abbreviations: BMI, body mass index; CRC, colorectal cancer; n, number; PA, Physical Activity; SD, standard deviation.

a Study participants were asked to report whether their current satisfaction with societal participation in paid job (yes/no), non-paid job (yes/no), household tasks

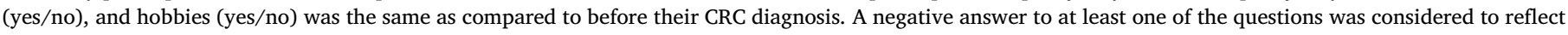
dissatisfaction with participation.

survivor decided to sport at home, as going out for sporting was too energy-consuming. For some CRC survivors who used to work/do odd jobs, treatment-induced fatigue and lack of muscle strength resulted in the inability to carry on with work activities, or the necessity to reduce working pace and -hours, and introducing frequent breaks (naps) to be able to continue work. As one person reported:

'After I was diagnosed with CRC, it took me one and a half years before I was able to work again. Fatigue was a major problem, and I still have to adapt my work pace and take several breaks during the day, by taking a rest or by taking a nap, to enable myself to continue my work'.

Fatigue restricted another participant in going on holidays. Survivors mentioned the necessity to consider fatigue as part of the daily life, and to spread energy-consuming tasks and events, as energy was limited.

Treatment-induced bowel complaints impacted participation as well. A change in defecation pattern, reaction of the bowel to specific foods, and incontinence were reported. One participant reported only leaving home after defecation (due to problems with continence), as he was afraid to soil himself, and another one made sure to restrict food and avoided specific foods which may cause problems on the day preceding the day the participant planned to go out to control defecation. For another participant, daily bowel lavage helped to control defecation again, and enabled him to work and travel again. In the next citation, he explains how he tried to keep his defecation under control:

'I have to limit some foods which may cause bowel complaints, like onions and red peppers. I also need to take care of the amounts of food I take. When I eat too much I may get bowel complaints and incontinence.'

One participant who had a stoma reported that the stoma bag restricted the ability for him to work in the garden. Another participant adapted the portion size when eating cabbage to restrict flatulence.

Lastly, several interviewees reported difficulties to return to work or the inability to work after and due to the CRC (treatment). Participation problems resulting from premature return to work (3 months after treatment) were reported by one survivor. Another person reported being fired after the CRC and regretted the fact that he was forced to stop with his work. One woman explained what losing her job meant to 
Table 2

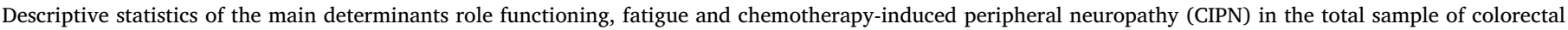
cancer survivors and in strata based on reported satisfaction with societal participation (yes/no).

\begin{tabular}{|c|c|c|c|c|c|c|c|}
\hline \multirow[t]{2}{*}{ Main Determinants } & & \multicolumn{2}{|c|}{ Total Sample } & \multicolumn{4}{|c|}{ Satisfaction With Societal Participation } \\
\hline & & & & Yes & & No & \\
\hline Physical role functioning, & $n(\%)$ Mean (SD) & 144 & $(38.2)$ & 118 & $(81.9)$ & 26 & $(18.1)$ \\
\hline RAND-36 subscale (scale: $0-100)^{\mathrm{a}}$ & & 73.1 & & 81.8 & $(32.0)$ & 33.7 & $(40.0)$ \\
\hline Emotional role functioning, & $n(\%)$ Mean (SD) & 148 & $(28.7)$ & 121 & $(81.8)$ & 27 & $(18.2)$ \\
\hline RAND-36 subscale (scale: $0-100)^{\mathrm{a}}$ & & 87.4 & & 93.1 & $(21.0)$ & 61.7 & $(42.0)$ \\
\hline Fatigue, & $n(\%)$ Mean (SD) & 149 & $(26.9)$ & 122 & (81.9) & 27 & (18.1) \\
\hline CIS (scale: $20-140)^{\mathrm{b}}$ & & 56.6 & & 52.1 & $(25.0)$ & 77.3 & $(26.1)$ \\
\hline \multicolumn{8}{|l|}{ Neuropathy, chemotherapy treatment ${ }^{\mathrm{C}}$} \\
\hline Sensory neuropathy & $n(\%)$ Mean (SD) & 71 & $(21.3)$ & 55 & $(77.5)$ & 16 & $(22.5)$ \\
\hline EORTC QLQ-CIPN20 subscale (scale: $0-100)^{\mathrm{d}}$ & & 21.6 & & 17.1 & $(18.0)$ & 37.0 & $(24.9)$ \\
\hline Motor neuropathy & $n(\%)$ Mean (SD) & 71 & $(22.3)$ & 55 & $(77.5)$ & 16 & $(22.5)$ \\
\hline EORTC QLQ-CIPN20 subscale (scale: $0-100)^{\mathrm{d}}$ & & 19.2 & & 14.3 & $(19.7)$ & 36.1 & $(23.2)$ \\
\hline Autonomic neuropathy & $n(\%)$ Mean (SD) & 72 & $(21.5)$ & 55 & $(76.4)$ & 17 & $(23.6)$ \\
\hline EORTC QLQ-CIPN20 subscale (scale: $0-100)^{\mathrm{d}}$ & & 15.5 & & 9.7 & $(17.7)$ & 34.3 & $(22.4)$ \\
\hline \multicolumn{8}{|l|}{ Neuropathy, no chemotherapy treatment $\mathrm{e}^{\mathrm{e}}$} \\
\hline Sensory neuropathy & $n(\%)$ Mean (SD) & 60 & $(14.0)$ & 51 & $(85.0)$ & 9 & $(15.0)$ \\
\hline EORTC QLQ-CIPN20 subscale (scale: $0-100)^{\mathrm{d}}$ & & 8.3 & & 5.8 & $(8.8)$ & 22.4 & $(26.2)$ \\
\hline Motor neuropathy & $n(\%)$ Mean (SD) & 60 & $(18.6)$ & 51 & $(85.0)$ & 9 & $(15.0)$ \\
\hline EORTC QLQ-CIPN20 subscale (scale: $0-100)^{\mathrm{d}}$ & & 11.8 & & 9.0 & (11.3) & 27.5 & (37.9) \\
\hline Autonomic neuropathy & $n(\%)$ Mean (SD) & 61 & $(15.0)$ & 52 & $(85.2)$ & 9 & $(14.8)$ \\
\hline EORTC QLQ-CIPN20 subscale (scale: $0-100)^{\mathrm{d}}$ & & 90.2 & & 8.3 & $(13.0)$ & 18.5 & $(22.7)$ \\
\hline
\end{tabular}

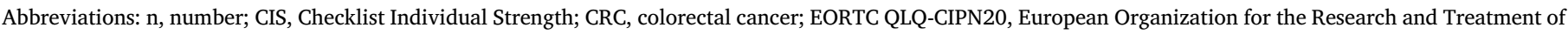
Cancer chemotherapy-induced peripheral neuropathy 20 item questionnaire; RAND-36, 36 item Health Survey questionnaire; SD, standard deviation.

a Higher score indicating a better physical and emotional role functioning, respectively.

b Higher score indicating a more complaints of fatigue.

c Results of study participants who received chemotherapy as part of their treatment for colorectal cancer.

d Higher score indicating a more symptoms of neuropathy.

e Results of study participants who did not receive chemotherapy as treatment for their colorectal cancer.

her:

'I was so happy with my new job. When I became ill, I received chemotherapy, and I developed a fracture of the arm, which did not heal well. The treatment also made me feel very tired. Therefore, I was not able to return to my work and this felt like a punishment to me. I miss my work and I miss the social contacts related to my work. I used to undertake many activities with my colleagues, but I lack the energy to be socially active.'

\section{Discussion}

In this mixed-method study, we analyzed whether role functioning, fatigue, and CIPN symptoms were associated with CRC survivors' satisfaction with participation. Nearly one in five long-term CRC survivors reported to be dissatisfied with their current level of participation 2-10 years post-diagnosis. Qualitative analyses of interviews suggested that several aspects of participation were restricted as a result of the prior CRC diagnosis and treatment. Additionally, CRC survivors reporting better role functioning were significantly less likely to be dissatisfied with their current level of participation, whereas survivors reporting higher levels of fatigue and more CIPN symptoms were more likely to be dissatisfied with participation. Additionally, we qualitatively explored the nature and impact of persisting health and functioning problems on participation of CRC survivors in everyday life situations.

Dissatisfaction with participation was reported by $19 \%$ of the CRC survivors, who considered their current ability to engage in jobs, domestic life and/or hobbies unsatisfactory. This shows that a majority of CRC survivors does not report dissatisfaction with these aspects of participation, and this is in line with a study of Domati, indicating that the majority of CRC survivors returned to normal life after 5 years (Domati et al., 2011). In our study persisting problems related to CIPN, fatigue, and bowel complaints resulting from the CRC diagnosis and treatment were reported to be related to the restricted participation. Thereby, these problems could have a huge impact on everyday life, limiting the ability to participate in working activities and other meaningful social activities. Results of a previous study using focus groups to explore concerns of (short-term) CRC survivors, showed that survivors were facing many challenges to adjust their lives and daily activities after diagnosis and treatment (Ho MY et al., 2015). The study of Desnoo et al. reports about difficulties in controlling and managing symptoms of rectal cancer, and another study among rectal cancer patients showed that work loss was significantly increased among stage III patients who had received neo-adjuvant radiotherapy or chemo-radiation (Chen et al., 2016; Desnoo and Faithfull, 2006). A review of Drury gives an overview of a range of issues in CRC survivorship, showing that CRC is a life-changing experience, with both positive and negative outcomes affecting physical, psychological and social wellbeing (Drury et al., 2017). Our findings are in line with these previous findings and provide additional insight into the impact of CRC- and treatment-related complaints on participation among those long-term CRC survivors who reported dissatisfaction with participation, raising awareness of the specific problems that these individuals face in their daily lives. In our study adjustments in activities of everyday life, due to effect of CRC (treatment) such as CIPN, fatigue, and bowel disfunction, were reported as well, affecting the ability to function and participate at home in household activities, and hobbies, and outside the house in work, in social contact and in social activities.

Data are emerging on relationships of socio-demographic characteristics, clinical factors, personality, and lifestyle factors with healthrelated outcomes in CRC survivors, such as health-related quality of life, fatigue, CIPN and physical and role functioning (Bours et al., 2016; Breedveld-Peters et al., 2018; Husson et al., 2015a,b; Packel et al., 2015; Rodriguez et al., 2015). Associations of elevated levels of fatigue persisting after the end of treatment with impaired functioning and 
Table 3

Adjusted odds Ratio's and 95\% confidence intervals of dissatisfaction with societal participation for the main determinants physical and emotional role functioning, fatigue and chemotherapy induced peripheral neuropathy (CIPN) in colorectal cancer survivors 2-10 Years post diagnosis, compared to before the cancer diagnosis.

\begin{tabular}{|c|c|c|c|c|}
\hline $\begin{array}{l}\text { Main } \\
\text { Determinants }\end{array}$ & $\begin{array}{l}\text { OR for } \\
\text { Dissatisfaction } \\
\text { with } \\
\text { Participation }^{\mathrm{e}}\end{array}$ & $(95 \% \mathrm{CI})$ & $\begin{array}{l}\text { OR for } \\
\text { Dissatisfaction }^{\mathrm{a}} \\
\text { with } \\
\text { Participation }^{\mathrm{f}}\end{array}$ & $(95 \% \mathrm{CI})$ \\
\hline $\begin{array}{l}\text { Physical role } \\
\text { functioning }\end{array}$ & 0.6 & $(0.5-0.8)$ & 0.7 & $(0.5-1.1)$ \\
\hline $\begin{array}{l}\text { Emotional role } \\
\text { functioning }\end{array}$ & 0.7 & $(0.5-0.8)$ & 0.9 & $(0.7-1.1)$ \\
\hline Fatigue $^{c}$ & 1.6 & $(1.2-2.0)$ & 1.2 & $(0.9-1.6)$ \\
\hline \multicolumn{5}{|l|}{ Neuropathy ${ }^{\mathrm{d}}$} \\
\hline - Sensory & 0.6 & $(0.5-0.8)$ & & \\
\hline - Motor & 0.6 & $(0.5-0.8)$ & & \\
\hline - Autonomy & 0.6 & $(0.5-0.8)$ & & \\
\hline \multicolumn{5}{|c|}{ Neuropathy ${ }^{\mathrm{d}}$ (in chemotherapy-treated survivors only) } \\
\hline - Sensory & 0.6 & $(0.5-0.9)$ & & \\
\hline - Motor & 0.6 & $(0.5-0.9)$ & & \\
\hline - Autonomy & 0.6 & $(0.4-0.8)$ & & \\
\hline
\end{tabular}

Abbreviations: CI, Confidence Interval; OR, Odds Ratio.

a Total score for dissatisfaction with societal participation including satisfaction with housework, hobbies, paid and non-paid job.

b Measured by the RAND 36-item Health Survey (RAND-36), with a higher score indicating a better physical or emotional role functioning.

c Measured by the Checklist Individual Strength (CIS), with a higher score indicating higher levels of fatigue.

d Measured by the European Organization for the Research and Treatment of Cancer Chemotherapy-Induced Peripheral Neuropathy 20-item questionnaire (EORTC QLQ-CIPN20), with a higher score indicating higher levels of specific neuropathy symptoms (sensory, motor or autonomy).

e Adjusted for age (years), gender, number of comorbidities $(0 / 1 / \geq 2)$, and chemotherapy treatment (yes/no).

$\mathrm{f}$ Additionally adjusted for the other determinants in the study: physical role functioning, emotional role functioning, and fatigue.

well-being have previously been reported (Husson et al., 2015a,b; Russell et al., 2015; Wang et al., 2014). Additionally, a recent review in a mixed cancer population (Mols et al., 2014a,b) reported that more CIPN symptoms are likely to be negatively associated with health-related quality of life outcomes. Other studies reported that CRC survivors suffering from CIPN complaints had deteriorated levels of physical activity and limited ability to perform activities of daily living (Packel et al., 2015; Padman et al., 2015; Tofthagen et al., 2013). Furthermore, the level of functioning has been reported to be inversely associated with the prior cancer diagnosis and treatment, showing a stronger decline in age-related health conditions and functioning in cancer survivors, including CRC survivors, as compared to age-matched controls (Leach et al., 2016). Lower role functioning was also shown in CRC survivors near the end of treatment (Russell et al., 2015). Lower physical, role- and physical functioning and global health status has been reported specifically for CRC survivors with ostomy (Mols ref). We now also found that common health and functioning problems experienced by many CRC survivors post-treatment, including low levels of role functioning and high levels of fatigue and more CIPN symptoms, were significantly associated with a lower satisfaction perceived by CRC survivors regarding their current level of participation. In this study we also found that main reported participation restrictions were linked to the inability to execute household activities, hobbies and sports due to CIPN. Participations restrictions in our study were also linked to the limitations in executing social activities and maintaining contacts, recreational activities and to work due to persisting fatigue, as well as the inability to go out due to bowel complaints (incontinence or stoma).
Table 4

Overview of characteristics of a subsample of colorectal cancer survivors from the EnCoRe study, who participated in the semi-structured interviews $(n=10)$.

\begin{tabular}{ll}
\hline Characteristic $^{\mathrm{a}}$ & Number of interview participants \\
\hline Age, years & 3 \\
$\quad<65$ & 7 \\
$\geq 65$ & \\
Gender & 6 \\
$\quad$ Male & 4 \\
$\quad$ Female & \\
Cancer stage & 4 \\
$\quad$ Stage I & 3 \\
Stage II & 2 \\
Stage III & \\
Having a stoma & 2 \\
Yes & 8 \\
$\quad$ No & \\
Years since diagnosis & 3 \\
$\quad<5$ & 7 \\
$\geq 5$ & \\
Number of comorbidities & 2 \\
0 & 1 \\
1 & 7 \\
$\geq 2$ & \\
Having a paid job & 2 \\
Yes & 8 \\
No & \\
Having a partner & 8 \\
Yes & 2 \\
No &
\end{tabular}

Abbreviations: EnCoRe study, Energy for life after ColoRectal Cancer study.

${ }^{a}$ These characteristics were used for the selection of interview candidates. Selection was based on the presence or absence of specific characteristics, in order to retrieve a mixed interview population in which all characteristics were represented.

This gives important additional insight in how participation restrictions affect daily live and functioning of CRC survivors, and may explain the lower satisfaction with societal participation found.

Healthcare services need to offer long-term follow up care to CRC survivors, to enable identification of health information and supportive care needs of those CRC survivors who suffer from a diversity of longterm health and functioning problems, that impact their ability to participate in activities of daily living and as a member of society. Both the quantitative and qualitative results suggest that there is a need to offer targeted evidence-based interventions to address problems adequately. Other studies emphasize the need to support individual CRC survivors in managing their disease, and address their met and unmet needs, to support their recovery as well (Drury et al., 2017; McCaughan et al., 2012). This starts with awareness amongst health care professionals of existing problems in CRC survivors. Based on identified physical and psychosocial problems a (multi modal) intervention program could be offered comprising for example a physical activity program to reduce fatigue, psychological support to cope with complaints, or reduce stress, and dietary advice to handle bowel complaints.

A main strength of the present study was our mixed-method approach. Next to the quantitative data, the qualitative data from face-toface interviews provided additional insight into the nature and impact of participation restrictions on everyday life as experienced by longterm CRC survivors. However, for measurement of satisfaction with participation, self-constructed items were used which may limit the reliability/validity of these items and thereby generalizability of findings. Also, satisfaction with participation in the quantitative analyses only reflects satisfaction with participation in paid job, non-paid job, household activities, and hobbies. Although the sample size was small and there was a risk of recall bias due to the retrospective questioning in the interviews, the factors identified in our explorative qualitative 


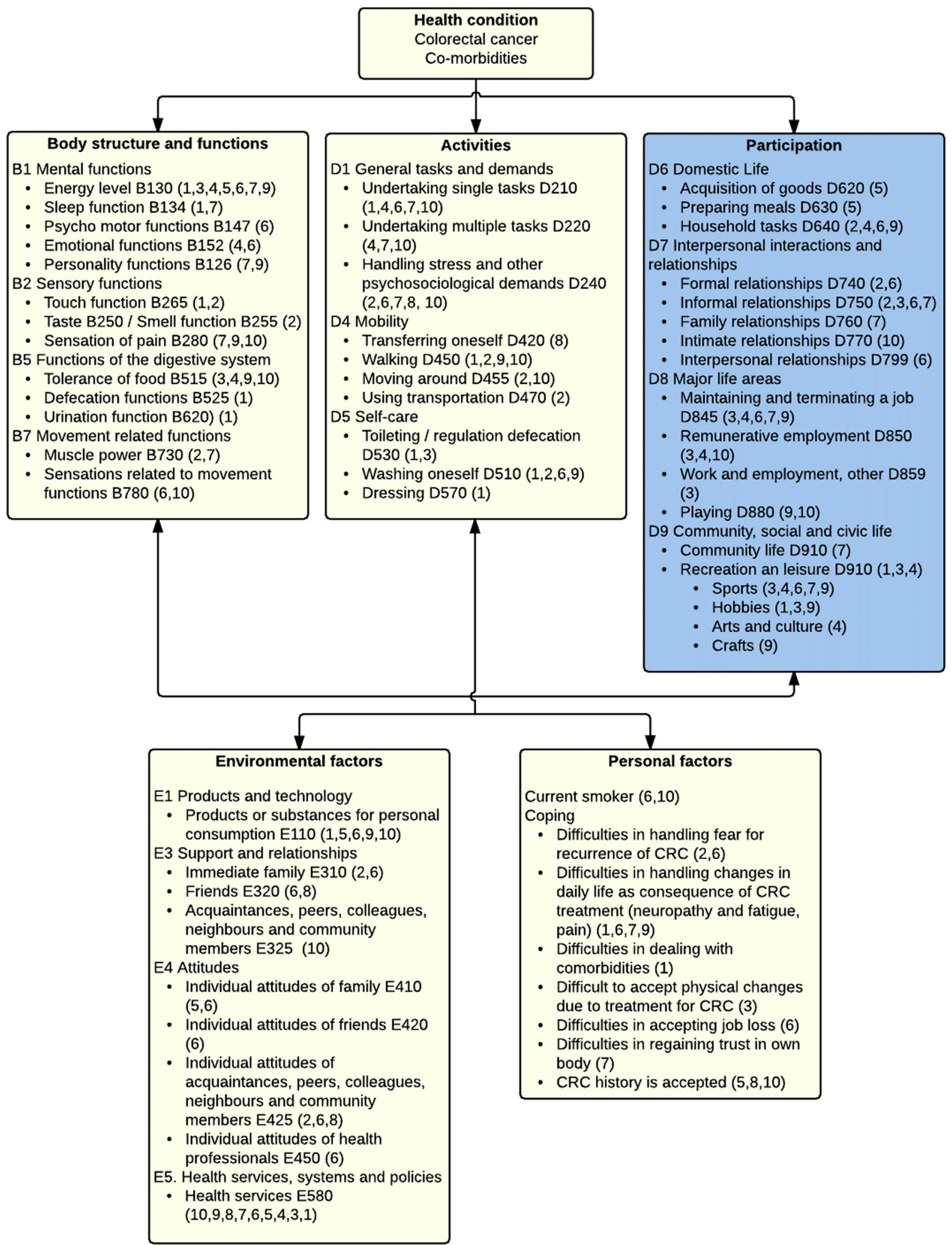

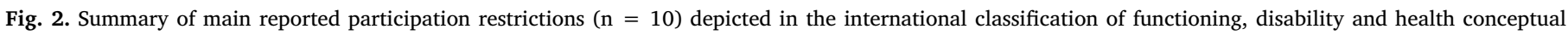
model.

Abbreviations: ICF, International Classification of Functioning, Disability and Health.

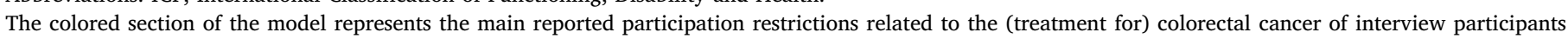

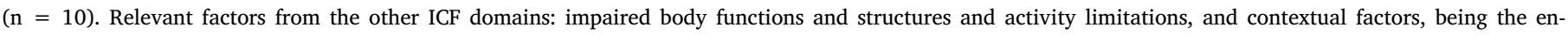
vironmental and personal factors influencing health and functioning, are presented as well. 


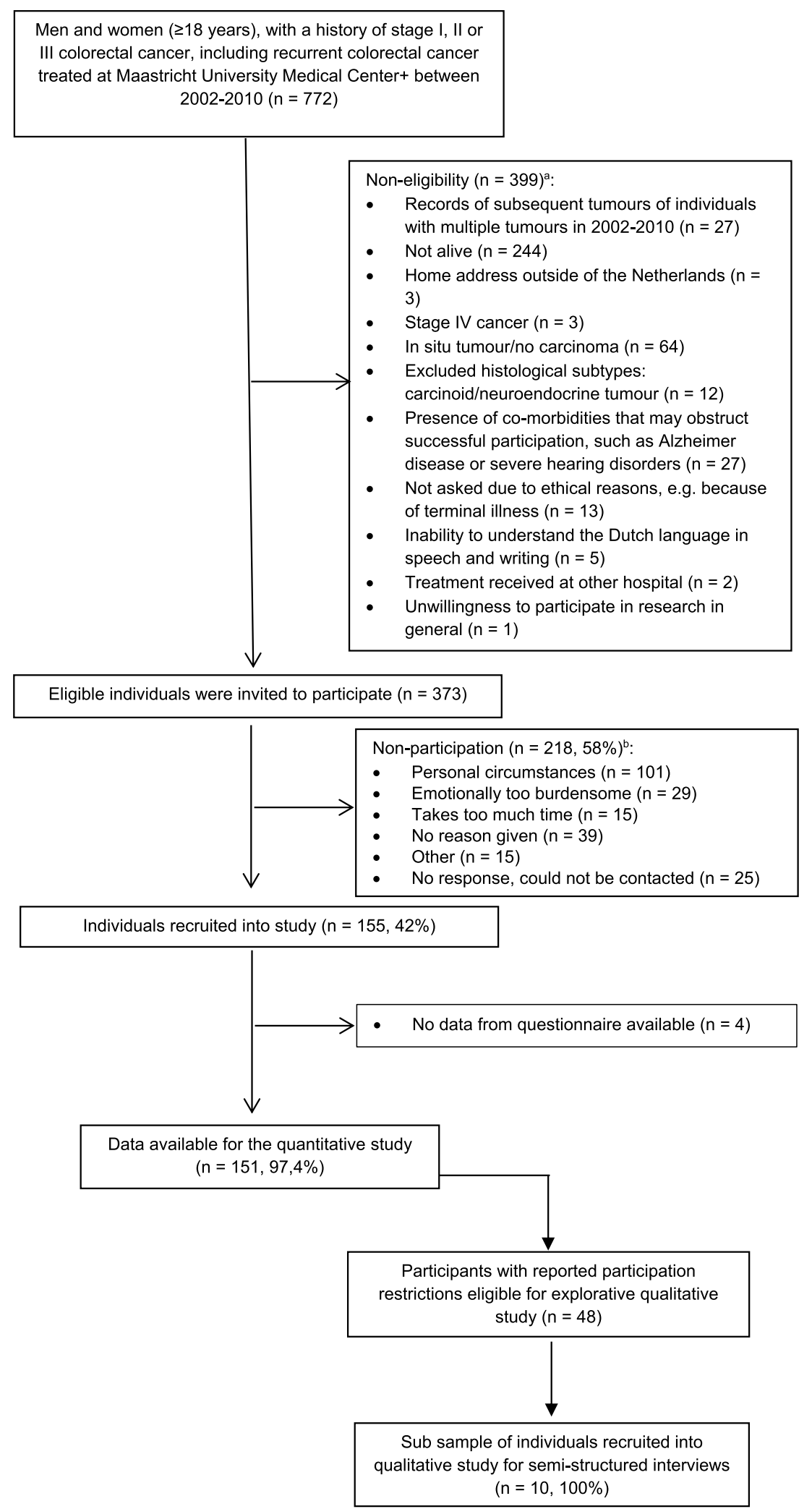

Fig. 3. Flow diagram of inclusion of individuals into the qualitative and quantitative parts of the present study.

${ }^{a}$ Reasons for non-eligibility are given in order of exclusion; totals do not add up because some exclusion criteria applied concurrently.

${ }^{\mathrm{b}}$ Totals do not add up because some individuals reported multiple reasons for non-participation.

study may inform future (prospective) studies in this area. A limitation of our study was its cross-sectional design. Consequently, the directionality of observed associations between health and functioning problems and CRC survivors' perceived satisfaction with participation should be interpreted with caution. A further limitation might have been that the response rate in the study was relatively low, and that our study population consisted mostly of relatively healthy CRC survivors 2-10 years post-diagnosis. Furthermore, despite the fact that we 
systematically linked interview questions on complaints related to the CRC diagnosis and its treatment, a limitation of this study may also be that we cannot rule out that interview participants have linked complaints for other medical conditions (comorbidities) to the CRC (treatment).

\section{Conclusions}

This study suggests that persisting health and functioning problems related to the prior CRC diagnosis and treatment in long-term CRC survivors can considerably restrict their participation in everyday life situations, as well as their feeling of satisfaction with their current level of participation. This study contributes to a better understanding of cancer- and treatment-related problems that long-term CRC survivors can face on a daily basis in their everyday life. This implies that CRC survivors need to be supported to enable them to manage their aftereffects of CRC. In the follow up care for CRC survivors, health professionals need to identify health information and supportive care needs of CRC survivors. Detections of problems CRC-survivors experience, and that affect their functioning and participation, can be integrated in routine follow up care visits. Extension of the period of follow up care may be needed for that. Furthermore, problems need to be adequately addresses with evidence based interventions in the area of physical health, psychological health, and social health. In this way survivors who suffer from long-term cancer- and treatment related problems affecting their functioning and participation, are supported to improve management of complaints. Future studies are needed to provide more insight of how to improve participation of CRC survivors.

\section{Research data for this article}

Due to the sensitive nature of the questions asked in the interviews in this study, interview respondents were assured raw data would remain confidential and would not be shared.

Quantitative data in this study from our ongoing EncoRe study is unavailable to access as these are confidential.

\section{Declaration of competing interest}

None declared.

\section{Acknowledgements}

We would like to thank Saeed Banaama, Claartje Broeren, Judith Ripken, Daniëlle Snijders, and Romée Tibosch, for their contribution to the study, regarding study design, development of study procedures and documents, execution of interviews, data entry and data analyses during their participation in the Honours Program 2013-2015 of the Bachelor Programs Medicine, Health Sciences and European Public Health of the Faculty of Health, Medicine and Life Sciences, Maastricht University.

We also would like to thank all funders for their financial support of the EnCoRe study.

This work was funded by a grant from the Alpe d'HuZes Foundation within the research program 'Leven met kanker' of the Dutch Cancer Society (Grant No. UM-2010-4867).

J.J.L. Breedveld-Peters is supported by a grant from Kankeronderzoekfonds Limburg (part of Health Foundation Limburg) (Grant No. 00005739).

M.J.L. Bours is supported by a grant from Kankeronderzoekfonds Limburg (part of Health Foundation Limburg) (Grant No. 00005739) and a grant from the Alpe d'HuZes Foundation within the research program 'Leven met kanker' of the Dutch Cancer Society (Grant No. UM-2012-5653).

\section{Appendix A. Supplementary data}

Supplementary data to this article can be found online at https:// doi.org/10.1016/j.ejon.2020.101724.

\section{References}

Aaronson, N.K., Muller, M., Cohen, P.D., Essink-Bot, M.L., Fekkes, M., Sanderman, R., Sprangers, M.A., te Velde, A., Verrips, E., 1998. Translation, validation, and norming of the Dutch language version of the SF-36 Health Survey in community and chronic disease populations. J. Clin. Epidemiol. 51 (11), 1055-1068.

Altschuler, A., Ramirez, M., Grant, M., Wendel, C., Hornbrook, M.C., Herrinton, L., Krouse, R.S., 2009. The influence of husbands' or male partners' support on women's psychosocial adjustment to having an ostomy resulting from colorectal cancer. J. Wound, Ostomy Cont. Nurs. 36 (3), 299-305. https://doi.org/10.1097/WON. 0b013e3181a1a1dc.

Averyt, J.C., Nishimoto, P.W., 2014. Psychosocial issues in colorectal cancer survivorship: the top ten questions patients may not be asking. J. Gastrointest. Oncol. 5 (5), 395-400. https://doi.org/10.3978/j.issn.2078-6891.2014.058.

Bols, E., Smits, L., Weijenberg, M., 2015. Healthy Living: the European Congress of Epidemiology, 2015. Abstract\#:P11 Jose J.L. Breedveld-Peters, Martijn J.L. Bours, Eline H. van Roekel, Silvia Sanduleanu, Geerard L. Beets, Matty P. Weijenberg. Associations of self-reported lifestyle advice, changes and enjoyment with health related quality of life in colorectal cancer survivors. Eur. J. Epidemiol. 30 (8), 709-1001. https://doi.org/10.1007/s10654-015-0072-z.

Bours, M.J., van der Linden, B.W., Winkels, R.M., van Duijnhoven, F.J., Mols, F., van Roekel, E.H., Kampman, E., Beijer, S., Weijenberg, M.P., 2016. Candidate predictors of health-related quality of life of colorectal cancer survivors: a systematic review. Oncol. 21 (4), 433-452. https://doi.org/10.1634/theoncologist.2015-0258.

Breedveld-Peters, J.J.L., Koole, J.L., Muller-Schulte, E., van der Linden, B.W.A., Windhausen, C., Bours, M.J.L., van Roekel, E.H., Weijenberg, M.P., 2018. Colorectal cancers survivors' adherence to lifestyle recommendations and cross-sectional associations with health-related quality of life. Br. J. Nutr. 1-10. https://doi.org/10. 1017/S0007114518000661.

Caravati-Jouvenceaux, A., Launoy, G., Klein, D., Henry-Amar, M., Abeilard, E., Danzon, A., Pozet, A., Velten, M., Mercier, M., 2011. Health-related quality of life among longterm survivors of colorectal cancer: a population-based study. Oncol. 16 (11) 1626-1636. https://doi.org/10.1634/theoncologist.2011-0036.

Catt, S., Starkings, R., Shilling, V., Fallowfield, L., 2017. Patient-reported outcome measures of the impact of cancer on patients' everyday lives: a systematic review. J. Canc. Surviv. 11 (2), 211-232. https://doi.org/10.1007/s11764-016-0580-1.

Chen, L., Glimelius, I., Neovius, M., Ekberg, S., Martling, A., Eloranta, S., Smedby, K.E., 2016. Work loss duration and predictors following rectal cancer treatment among patients with and without prediagnostic work loss. Canc. Epidemiol. Biomarkers Prev. 25 (6), 987-994. https://doi.org/10.1158/1055-9965.EPI-16-0112.

Denlinger, C.S., Barsevick, A.M., 2009. The challenges of colorectal cancer survivorship. J. Natl. Compr. Canc. Netw. 7 (8), 883-893 quiz 894.

Desnoo, L., Faithfull, S., 2006. A qualitative study of anterior resection syndrome: the experiences of cancer survivors who have undergone resection surgery. Eur. J. Canc. Care 15 (3), 244-251. https://doi.org/10.1111/j.1365-2354.2005.00647.x.

Devins, G.M., Bezjak, A., Mah, K., Loblaw, D.A., Gotowiec, A.P., 2006. Context moderates illness-induced lifestyle disruptions across life domains: a test of the illness intrusiveness theoretical framework in six common cancers. Psycho Oncol. 15 (3), 221-233. https://doi.org/10.1002/pon.940.

Domati, F., Rossi, G., Benatti, P., Roncucci, L., Cirilli, C., Ponz de Leon, M., 2011. Long term survey of patients with curable colorectal cancer with specific reference to the quality of life. Intern. Emerg. Med. 6 (6), 529-535. https://doi.org/10.1007/s11739011-0590-y.

Drury, A., Payne, S., Brady, A.M., 2017. Cancer survivorship: advancing the concept in the context of colorectal cancer. Eur. J. Oncol. Nurs. 29, 135-147. https://doi.org/ 10.1016/j.ejon.2017.06.006.

Dunn, J., Ng, S.K., Breitbart, W., Aitken, J., Youl, P., Baade, P.D., Chambers, S.K., 2013. Health-related quality of life and life satisfaction in colorectal cancer survivors: trajectories of adjustment. Health Qual. Life Outcome 11, 46. https://doi.org/10.1186/ 1477-7525-11-46.

Etikan, I., 2016. Comparison of convenience sampling and purposive sampling. Am. J.Appl. Stat. 5 (1), 1-4. https://doi.org/10.11648/j.ajtas.20160501.11.

Field, A., 2013. Discovering Statistis Using IBM SPSS Statistics. SAGE, London.

Fitzsimmons, D., Gilbert, J., Howse, F., Young, T., Arrarras, J.I., Bredart, A., Hawker, S., George, S., Aapro, M., Johnson, C.D., 2009. A systematic review of the use and validation of health-related quality of life instruments in older cancer patients. Eur. J. Canc. 45 (1), 19-32. https://doi.org/10.1016/j.ejca.2008.07.036.

Forman, J., Damschroder, L., 2008. Qualitative content analysis. In: Empirical Methods for Bioethics: A Primer. Elsevier Ltd., pp. 39-62.

Grant, M., McMullen, C.K., Altschuler, A., Mohler, M.J., Hornbrook, M.C., Herrinton, L.J., Wendel, C.S., Baldwin, C.M., Krouse, R.S., 2011. Gender differences in quality of life among long-term colorectal cancer survivors with ostomies. Oncol. Nurs. Forum 38 (5), 587-596. https://doi.org/10.1188/11.ONF.587-596.

Harrington, C.B., Hansen, J.A., Moskowitz, M., Todd, B.L., Feuerstein, M., 2010. It's not over when it's over: long-term symptoms in cancer survivors-a systematic review. Int. J. Psychiatr. Med. 40 (2), 163-181.

Ho My, M.B.M., Gotay, C., Grunfeld, E., Earle, C.C., Relova, S., Tsonis, M., Ruan, J.Y., Chang, J.T., Cheung, W.Y., 2015. A qualitative focus group stuyd to identify the needs of survivors of stage II and III colorectal cancer. Psycho Oncol. https://doi.org/ 
10.1002/pon.3988

Husson, O., Mols, F., van de Poll-Franse, L.V., Thong, M.S., 2015a. The course of fatigue and its correlates in colorectal cancer survivors: a prospective cohort study of the PROFILES registry. Support. Care Canc. 23 (11), 3361-3371. https://doi.org/10. 1007/s00520-015-2802-x.

Husson, O., Vissers, P.A., Denollet, J., Mols, F., 2015b. The role of personality in the course of health-related quality of life and disease-specific health status among colorectal cancer survivors: a prospective population-based study from the PROFILES registry. Acta Oncol. 54 (5), 669-677. https://doi.org/10.3109/0284186X.2014. 996663.

Jansen, L., Koch, L., Brenner, H., Arndt, V., 2010. Quality of life among long-term ( $>/=5$ years) colorectal cancer survivors-systematic review. Eur. J. Canc. 46 (16), 2879-2888. https://doi.org/10.1016/j.ejca.2010.06.010.

Kostanjsek, N., 2011. Use of the International Classification of Functioning, Disability and Health (ICF) as a conceptual framework and common language for disability statistics and health information systems. BMC Publ. Health 11 (Suppl. 4). https://doi.org/10. 1186/1471-2458-11-S4-S3. S3.

Leach, C.R., Bellizzi, K.M., Hurria, A., Reeve, B.B., 2016. Is it my cancer or am i just getting older?: impact of cancer on age-related health conditions of older cance survivors. Cancer 122 (12), 1946-1953. https://doi.org/10.1002/cncr.29914.

LeMasters, T.J., Madhavan, S.S., Sambamoorthi, U., Kurian, S., 2014. Health behaviors among breast, prostate, and colorectal cancer survivors: a US population-based casecontrol study, with comparisons by cancer type and gender. J. Canc. Surviv. 8 (3), 336-348. https://doi.org/10.1007/s11764-014-0347-5.

McCaughan, E., Prue, G., Parahoo, K., McIlfatrick, S., McKenna, H., 2012. Exploring and comparing the experience and coping behaviour of men and women with colorectal cancer after chemotherapy treatment: a qualitative longitudinal study. Psycho Oncol. 21 (1), 64-71. https://doi.org/10.1002/pon.1871.

McGrath, C., Mihala, G., Beesley, V.L., Lynch, B.M., Graves, N., Gordon, L.G., 2017. Cancer put my life on hold": work-related challenges among middle-aged adults 12 Months after a diagnosis of colorectal cancer. Canc. Nurs. 40 (2), 160-167. https:// doi.org/10.1097/NCC.0000000000000359.

McMullen, C.K., Hornbrook, M.C., Grant, M., Baldwin, C.M., Wendel, C.S., Mohler, M.J., Altschuler, A., Ramirez, M., Krouse, R.S., 2008. The greatest challenges reported by long-term colorectal cancer survivors with stomas. J. Support Oncol. 6 (4), 175-182.

Mols, F., Beijers, T., Vreugdenhil, G., van de Poll-Franse, L., 2014a. Chemotherapy-induced peripheral neuropathy and its association with quality of life: a systematic review. Support. Care Canc. 22 (8), 2261-2269. https://doi.org/10.1007/s00520014-2255-7.

Mols, F., Lemmens, V., Bosscha, K., van den Broek, W., Thong, M.S., 2014b. Living with the physical and mental consequences of an ostomy: a study among 1-10-year rectal cancer survivors from the population-based PROFILES registry. Psycho Oncol. 23 (9), 998-1004. https://doi.org/10.1002/pon.3517.

Nikoletti, S., Young, J., Levitt, M., King, M., Chidlow, C., Hollingsworth, S., 2008. Bowel problems, self-care practices, and information needs of colorectal cancer survivors at 6 to 24 months after sphincter-saving surgery. Canc. Nurs. 31 (5), 389-398. https:// doi.org/10.1097/01.NCC.0000305759.04357.1b.

Packel, L.B., Prehn, A.W., Anderson, C.L., Fisher, P.L., 2015. Factors influencing physical activity behaviors in colorectal cancer survivors. Am. J. Health Promot. 30 (2), 85-92. https://doi.org/10.4278/ajhp.140103-QUAN-7.

Padman, S., Lee, J., Kumar, R., Slee, M., Hakendorf, P., Richards, A., Koczwara, B., Kichenadasse, G., Sukumaran, S., Roy, A., Vatandoust, S., Karapetis, C.S., 2015. Late effects of oxaliplatin-induced peripheral neuropathy (LEON)-cross-sectional cohort study of patients with colorectal cancer surviving at least 2 years. Support. Care Canc. 23 (3), 861-869. https://doi.org/10.1007/s00520-014-2423-9.

Ramirez, M., McMullen, C., Grant, M., Altschuler, A., Hornbrook, M.C., Krouse, R.S., 2009. Figuring out sex in a reconfigured body: experiences of female colorectal cancer survivors with ostomies. Women Health 49 (8), 608-624. https://doi.org/10. 1080/03630240903496093.

Rasmussen, D.M., Elverdam, B., 2008. The meaning of work and working life after cancer: an interview study. Psycho Oncol. 17 (12), 1232-1238. https://doi.org/10.1002/ pon. 1354.

Revicki, D., Hays, R.D., Cella, D., Sloan, J., 2008. Recommended methods for determining responsiveness and minimally important differences for patient-reported outcomes. J. Clin. Epidemiol. 61 (2), 102-109. https://doi.org/10.1016/j.jclinepi.2007.03.012.
Rodriguez, J.L., Hawkins, N.A., Berkowitz, Z., Li, C., 2015. Factors associated with healthrelated quality of life among colorectal cancer survivors. Am. J. Prev. Med. 49 (6 Suppl. 5), S518-S527. https://doi.org/10.1016/j.amepre.2015.08.007.

Russell, L., Gough, K., Drosdowsky, A., Schofield, P., Aranda, S., Butow, P.N., Westwood, J.A., Krishnasamy, M., Young, J.M., Phipps-Nelson, J., King, D., Jefford, M., 2015. Psychological distress, quality of life, symptoms and unmet needs of colorectal cancer survivors near the end of treatment. J. Canc. Surviv. 9 (3), 462-470. https://doi.org/ 10.1007/s11764-014-0422-y.

Sangha, O., Stucki, G., Liang, M.H., Fossel, A.H., Katz, J.N., 2003. The Self-Administered Comorbidity Questionnaire: a new method to assess comorbidity for clinical and health services research. Arthritis Rheum. 49 (2), 156-163. https://doi.org/10.1002/ art.10993.

Servaes, P., van der Werf, S., Prins, J., Verhagen, S., Bleijenberg, G., 2001. Fatigue in disease-free cancer patients compared with fatigue in patients with chronic fatigue syndrome. Support. Care Canc. 9 (1), 11-17.

Smith, E.M.L., Banerjee, T., Yang, J.J., Bridges, C.M., Alberti, P., Sloan, J.A., Loprinzi, C., 2019. Testing of the European organisation for research and treatment of cancer quality of life questionnaire-chemotherapy-induced peripheral neuropathy 20 -item scale using pooled chemotherapy-induced peripheral neuropathy outcome measures standardization and alliance for clinical trials in oncology A151408 study data. Canc. Nurs. 42, 179-189.

Smith, E.M.L., Knoerl, R., Yang, J.J., Kanzawa-Lee, G., Lee, D., Bridges, C.M., 2018. In search of a gold standard patient-reported outcome measure for use in chemotherapyinduced peripheral neuropathy clinical trials. Canc. Cont. 25 (1073274818756608).

Stephenson, R., Richardson, B., 2008. Building an interprofessional curriculum framework for health: a paradigm for health function. Adv. Health Sci. Edu. Theor. Pract. 13 (4), 547-557. https://doi.org/10.1007/s10459-006-9042-2.

Stine, R.A., 1995. Graphical interpretation of variance inflation factors. Am. Statistician 49 (1), 53-56.

Sweeney, C., Schmitz, K.H., Lazovich, D., Virnig, B.A., Wallace, R.B., Folsom, A.R., 2006 Functional limitations in elderly female cancer survivors. J. Natl. Cancer Inst. 98 (8), 521-529. https://doi.org/10.1093/jnci/djj130.

Tofthagen, C., Donovan, K.A., Morgan, M.A., Shibata, D., Yeh, Y., 2013. Oxaliplatin-induced peripheral neuropathy's effects on health-related quality of life of colorectal cancer survivors. Support. Care Canc. 21 (12), 3307-3313. https://doi.org/10.1007/ s00520-013-1905-5.

van Roekel, E.H., Bours, M.J., de Brouwer, C.P., Ten Napel, H., Sanduleanu, S., Beets, G.L., Kant, I.J., Weijenberg, M.P., 2014. The applicability of the international classification of functioning, disability, and health to study lifestyle and quality of life of colorectal cancer survivors. Canc. Epidemiol. Biomarkers Prev. 23 (7), 1394-1405. https://doi.org/10.1158/1055-9965.EPI-13-1144.

VanDerzee, K.I., Sanderman, R., Het meten van de algemene gezondheidstoestand met de RAND-36 Een handleiding. In: NCG Reeks Meetinstrumenten ; 3. Noordelijk Centrum Voor Gezondheidsvraagstukken, NCG, Rijksuniversiteit Groningen, Groningen.

Vercoulen, J.H., Hommes, O.R., Swanink, C.M., Jongen, P.J., Fennis, J.F., Galama, J.M., van der Meer, J.W., Bleijenberg, G., 1996. The measurement of fatigue in patients with multiple sclerosis. A multidimensional comparison with patients with chronic fatigue syndrome and healthy subjects. Arch. Neurol. 53 (7), 642-649.

Vercoulen, J.H., Swanink, C.M., Fennis, J.F., Galama, J.M., van der Meer, J.W., Bleijenberg, G., 1994. Dimensional assessment of chronic fatigue syndrome. J. Psychosom. Res. 38 (5), 383-392.

Wang, X.S., Zhao, F., Fisch, M.J., O'Mara, A.M., Cella, D., Mendoza, T.R., Cleeland, C.S., 2014. Prevalence and characteristics of moderate to severe fatigue: a multicenter study in cancer patients and survivors. Cancer 120 (3), 425-432. https://doi.org/10. 1002 /cner. 28434.

Ware Jr., J.E., Sherbourne, C.D., 1992. The MOS 36-item short-form health survey (SF36). I. Conceptual framework and item selection. Med. Care 30 (6), 473-483.

Wendel-Vos, G.C., Schuit, A.J., Saris, W.H., Kromhout, D., 2003. Reproducibility and relative validity of the short questionnaire to assess health-enhancing physical activity. J. Clin. Epidemiol. 56 (12), 1163-1169.

World Health Organization, 2001. International Classification of Functioning, Disability and Health: ICF. World Health Organization, Geneva, Switserland.

Wright, E.P., Kiely, M., Johnston, C., Smith, A.B., Cull, A., Selby, P.J., 2005. Development and evaluation of an instrument to assess social difficulties in routine oncology practice. Qual. Life Res. 14 (2), 373-386. 